\title{
A PRODUÇÃO TEXTUAL E AS NOVAS TECNOLOGIAS: O USO DE BLOGS PARA A ESCRITA COLABORATIVA
}

\begin{abstract}
Solimar Patriota Silva é professora da Universidade do Grande Rio (UNIGRANRIO) e doutoranda em Linguística Aplicada pela UFRJ. Seus interesses de pesquisa envolvem, gêneros discursivos; ensino de línguas; formação docente, em especial dos mediadores de leitura, no contexto digital, para atuar com educação a distância ou utilizando os recursos das novas tecnologias no contexto presencial.

E-mail: solimar.silva@unigranrio.com.br
\end{abstract}

Anna Paula Bahia Pessanha é graduada em Letras (Português-Literatura) e especialista em Língua Portuguesa (UNIGRANRIO). Atualmente, atua como professora das redes particular e pública de ensino no Rio de Janeiro.

E-mail: apb.pessanha@hotmail.com

\section{Resumo}

O presente artigo objetiva apresentar uma discussão teórica acerca de como o ensino de produção textual em língua materna pode ser realizado através da utilização dos recursos das novas tecnologias da informação e comunicação (NTICs), especificamente com a criação de blogs coletivos. Desta maneira, pretende-se contribuir com uma aproximação da escola com os recursos tecnológicos no ensino, de modo a contribuir com o letramento digital do aluno e incentivar a escrita de gêneros textuais diversos no contexto digital.

\begin{abstract}
This article aims to present a theoretical discussion on teaching writing to native speakers and how this can be accomplished through the use of the capabilities of new information and communication technologies (NICTs), specifically using collective blogging. In this way, we intend to contribute with an approximation of the school with the technological resources in education, so as to enrich students' digital literacy and encourage the writing of various genres in the digital context
\end{abstract}

\section{1) Introdução}

Com o mundo cada vez mais globalizado e, consequentemente, com o surgimento de novas tecnologias, o computador se tornou um forte aliado das escolas como um instrumento pedagógico que ajuda na construção do conhecimento tanto dos alunos quanto dos professores, ampliando o potencial da metodologia empregada nas aulas e fazendo da prática pedagógica algo bastante atrativo.

Conforme apontam Freitas e Costa (2006, p. 8), "os novos suportes e instrumentos culturais da contemporaneidade, como o computador e a internet, têm-se tornado mediadores de outras alternativas de leitura e escrita". Neste sentido, há cada vez mais a preocupação em tornar dinâmico o processo de ensino e aprendizagem, com projetos interativos que usem a rede eletrônica.

A internet é uma grande fonte de lazer, que possibilita fazer pesquisas, ler notícias, ver imagens, "visitar" museus e bibliotecas virtualmente, conhecer e "bater papo" com pessoas do mundo inteiro. De acordo com Murano (2011, p. 28) o número de usuários que acessam a rede no Brasil aumentou 35\% entre os anos 2008 e 2009. Ainda segundo ele, "não é exagero afirmar que $e$-mails, blogs e redes de relacionamento já deixaram sua marca na produção textual contemporânea".

Partindo deste pressuposto, é importante questionar-se a respeito de como trabalhar a produção de texto por meio das ferramentas digitais, visto que a internet vem criando novos hábitos de comunicação entre as pessoas por meio da escrita. A possibilidade e a facilidade que uma pessoa tem de escrever, editar e publicar seus 
próprios textos em redes sociais como o Orkut e o Facebook, ou através de blogues, por exemplo, deve ser mais bem aproveitada no contexto de ensino-aprendizagem da língua materna.

Ao tecer suas considerações sobre o texto na era digital, Murano (2011, p. 33) afirma que "com os recursos de interação cada vez mais expandidos, qualquer site é um convite a comentários, críticas e observações, obrigando os internautas a desenvolverem discursos de improviso e a defender seus pontos de vista", isto porque a internet nos oferece grandes possibilidades de leitura e escrita de diversos gêneros discursivos.

Este artigo tem como objetivo demonstrar que as novas tecnologias presentes na sociedade, se usadas adequadamente, colaboram para alavancar mudanças que podem contribuir para o aluno ler, criar, se expressar por meio da produção textual, mostrando que a internet pode trabalhar a linguagem escrita de forma prazerosa e interessante, ao mesmo temo em que favorece um processo de inclusão digital e social.

Muito mais que gírias e jargões como o "internetês", caracterizado por uma linguagem informal e de uso coletivo em que são utilizados recursos tais como abreviações e reduções de palavras, emoticons, alongamentos de vogais, de modo com que se expressem os pensamentos de forma um tanto quanto mais rápida, ela pode desenvolver nos estudantes grandes habilidades para a escrita.

\section{2) Produção Textual}

A escrita é uma das formas de comunicação humana que está presente em nosso dia a dia, seja em casa, na rua, na escola ou no trabalho, mas nem sempre foi assim. Conforme apontam Koch e Elias (2011, p. 31), se hoje vivemos em uma "cultura gráfica”, durante muitos anos o comum era a existência de comunidades ágrafas, onde o homem se expressava apenas por meio da linguagem oral, pela expressão corporal, por meio de gestos e símbolos. A escrita era de difícil acesso e destinada a poucos privilegiados.

Com o passar do tempo o homem foi descobrindo a grafia na forma de escrita propriamente dita, por intermédio dos povos egípcios e mesopotâmicos. Tal fato pode ser considerado como uma grande tecnologia da comunicação. Segundo Freitas (2006, p. 12), da mesma forma que o surgimento da escrita pode ter trazido questionamentos sobre os efeitos na capacidade de memória na sociedade cuja base da comunicação era a oralidade, hoje em dia, a informática tem provocado resistência, por parte de algumas pessoas, que talvez vejam o livro ou o texto impresso, em geral, cedendo lugar para essa nova forma de leitura e escrita que as novas tecnologias têm proporcionado.

Percebida como produto sócio-histórico-cultural, a escrita é a codificação da linguagem oral, é a representação gráfica do pensamento e da palavra. É por meio da escrita que atualmente registramos nossas ideias e, por conseguinte, nos comunicamos. Escrevemos e lemos diversos tipos de textos, como bilhetes, e-mails, listas de compras e outros. Entretanto, apesar de ser onipresente em nossas vidas, o ato de escrever e expressar nossos pensamentos, intenções e experiências no papel não costuma ser tarefa fácil para ninguém, ao contrário, é algo bastante complexo, bem como a própria linguagem. "Aprendê-la é aprender não somente palavras e saber combiná-las em expressões complexas, mas apreender pragmaticamente seus significados culturais e, com eles, os modos pelos quais as pessoas entendem e interpretam a realidade e a si mesmas" (PCN-LP, 1998, p. 20).

Escrever um texto não significa apenas "jogar" as palavras no papel, mas dar sentido a elas. Durante o ato da escrita deve-se levar em conta alguns pontos como a 
quem ele se destinará, o tipo de escrita que deverá ser utilizado, a mensagem que se quer transmitir. Para Koch e Elias (2011, p. 36) a escrita é "um trabalho no qual o sujeito tem algo a dizer e o faz sempre em relação a outro (o seu interlocutor/ leitor) com certo propósito".

Normalmente as pessoas possuem certa dificuldade ao iniciar um texto, isto porque, segundo Guerreiro (2011, p. 37), estamos muito mais familiarizados com a linguagem oral do que com a linguagem escrita, ou seja, escrever não é tão simples como falar.

Pode ser que algumas experiências durante a fase escolar acabem por contribuir com esse quadro. Muitos são os alunos que têm medo de transformar seus pensamentos para a forma escrita. E será mais desafiador vencer essa barreira se o tema da "redação" for algo como 'suas férias', tema tão comum até recentemente no período de volta às aulas.

Muitos ficam na dúvida sobre o que escrever e como escrever. Ler muito, rascunhar, errar, reescrever, são atividades pouco exploradas na escola. Afinal, acreditamos que não exista uma fórmula mágica para escrever um texto. O importante é refletir, é organizar os pensamentos de forma que o texto possa ter significado para quem o escreve. Desta forma ele será desenvolvido com maior facilidade. Castilho (2011, p. 46) destaca a frase "escrever é um labirinto cuja dificuldade não é encontrar a saída, mas a entrada", atribuída ao Rubem Fonseca. E essa entrada pode ser encontrada com a prática da escrita e da reescrita no espaço escolar, onde o texto não é visto como pretexto apenas para o treino das regras de ortografia, mas, principalmente, como meio de exposição de ideias, desenvolvimento do poder de argumentação, síntese, criticidade e expressão da subjetividade do escritor.

\section{1) A evolução da escrita - da pedra ao computador}

Podemos considerar que a escrita foi e ainda representa uma das maiores realizações do homem, ao avaliarmos a importância que ela tem em nosso cotidiano e as funções que desempenha em nossa sociedade. Segundo Sampson (1996), desde o seu surgimento até os dias atuais, a linguagem escrita já passou por muitas mudanças que vaão desde a fase pictórica (desenhos daquilo o que se quer representar) e a ideográfica (símbolos gráficos que representam uma ideia) até a fase alfabética (utilização das letras).

Para Andrade (2001), estamos tão acostumados a ler e a escrever, rodeados por uma vasta diversidade de textos, que torna-se até mesmo impossível imaginarmos nossas vidas sem a escrita. Entretanto, em tempos remotos era assim e, se antes viver sem a escrita era possível, é porque o contexto era outro e as necessidades humanas também. Mas à medida que o homem foi se desenvolvendo como ser humano, precisou também ampliar tudo o que estava em seu entorno. E foi pela necessidade em se expressar e representar seus pensamentos, opiniões e nossa própria história é que a escrita foi criada.

Antigamente, apenas as pessoas que faziam parte da elite tinham acesso à educação e, por conseguinte, à escrita. Hoje ela já é acessível a praticamente toda a população (Koch e Elias, 2011, p. 31). O domínio da linguagem, como atividade discursiva e cognitiva, e o domínio da língua, como sistema simbólico utilizado por uma comunidade linguística, são condições de possibilidade de plena participação social. Pela linguagem os homens e as mulheres se comunicam, têm acesso à informação, expressam e defendem pontos de vista, partilham ou constroem visões de mundo, produzem cultura (PCN-LP. 1998, p. 20). 
Com o advento da internet, maior rede de comunicação e informação já criada, novas formas e práticas de escrita vêm sendo desenvolvidas com características próprias e específicas. A escrita está sendo cada vez mais utilizada e as formas de se comunicar, ampliadas. São milhares de pessoas conectadas à rede por meio de chats, e-mails e outros programas de comunicação, que transmitem e recebem informações diariamente.

As novas tecnologias e as interações entre diferentes suportes e linguagens (verbal ou não verbal) nos permite contar hoje com novas estratégias didáticas para se trabalhar com textos digitais na sala de aula e possibilita até mesmo o aparecimento de formas coletivas de construção de textos, conforme afirma Freitas (2006, p. 17). A Wikipédia, enciclopédia livre, é um belo exemplo de escrita colaborativa na internet, uma comunidade virtual onde qualquer usuário que por ela navega pode acessar e editar as informações ali contidas, acrescentando dados novos aos documentos.

\section{2) O Ensino de Produção de Texto}

Escrever é uma atividade que leva certo tempo, consumindo boa parte de nossas horas dependendo do que se vai produzir. Exige um pouco mais de concentração e o escritor não pode, em momento algum, deixar de se preocupar com o seu leitor. Se o leitor não compreende o sentido do texto e seu propósito, significa que de alguma forma o escritor não conseguiu configurar na escrita a sua intenção de forma que possibilitasse o fácil reconhecimento do objetivo do texto.

Com o mundo cada vez mais letrado, hoje o grande desafio das escolas é formar alunos praticantes tanto da leitura quanto da escrita. No Ensino de Língua Portuguesa, o que vem sendo bastante trabalhado atualmente é a produção textual e, desde as séries iniciais, o texto coletivo já se faz presente, de modo a desenvolver nos alunos a criatividade e aprimorar o modo como se expressam na linguagem escrita. Visto que vivemos em uma sociedade que requer dos alunos conhecimentos muito mais vastos do que a mera reprodução de conteúdos, cabe ao aluno hoje saber ler, interpretar, criar e recriar, produzir, expressar e comunicar suas ideias.

Fazer com que os alunos sejam capazes de interpretar os diferentes textos que circulam socialmente, assumir a palavra e, como cidadãos, produzir textos eficazes nas mais variadas situações, tem sido a proposta do Ensino de Língua Portuguesa e requer um trabalho intenso por parte do professor. O texto tem sido o ponto de partida nas escolas, já que os níveis de leitura e de escrita são exigidos em demandas diferentes do que satisfaziam até bem pouco tempo.

Segundo os Parâmetros Curriculares Nacionais de Língua Portuguesa (1998, p. 23), "a compreensão oral e escrita, bem como a produção oral e escrita de textos pertencentes a diversos gêneros, supõem o desenvolvimento de diversas capacidades que devem ser enfocadas nas situações de ensino". Portanto, o professor deve familiarizar os alunos com o mundo dos textos e estimular sua escrita de forma adequada, levando-os a selecionar as palavras mais apropriadas para formular uma mensagem compreensível para quem a receberá, de modo que não haja repetições ou dupla interpretação. Também cabe ao professor fazer com que os alunos desenvolvam habilidades para a elaboração de textos com coerência e coesão, por meio de uma formação continuada.

É necessário ampliar a competência discursiva do aluno na interlocução e, para que ele aprenda a escrever, faz-se mister que ele tenha contato com a uma gama variada de textos escritos em sua diversidade de gêneros, não apenas pela sua relevância social, mas também porque textos de diferentes gêneros são organizados de diferentes formas e ampliam o conhecimento e o repertório do aluno. 
Os gêneros textuais existem em número praticamente ilimitado, pois variam de acordo com a época, a cultura e a finalidade social. A Internet é um meio eletrônico que vem cada vez mais introduzindo os alunos no mundo da escrita, visto que a comunicação no meio digital se dá predominantemente através da palavra escrita e novos gêneros discursivos emergentes (Marchuschi, 2010) surgem a cada dia. As novas tecnologias podem ser utilizadas para atrair a atenção dos alunos, a fim de que eles produzam textos de modo interativo, dinâmico e "vivo" (Freitas, 2006, pp.11-17).

A leitura e a escrita no meio digital têm dado ao ensino de Língua Portuguesa uma nova dimensão por torná-lo mais fluido e dinâmico. Embora o livro impresso tenha sido historicamente o meio mais importante de difusão de saberes, atualmente eles deixaram de ser apenas impressos e passaram a ser distribuídos por meio eletrônico através de e-books diversos, que podem ser lidos no Ipad ou Tablet.

Saber utilizar fontes variadas de informação e recursos tecnológicos para adquirir e construir conhecimento contribui também para que se utilize a língua de modo variado e mais atuante. Os meios tecnológicos, principalmente aqueles disponíveis com as Novas Tecnologias da Informação e da Comunicação (NTICs), determinam novas organizações textuais e visuais, modificando a relação do leitor com o texto.

\section{3) Novas Tecnologias e Escrita: Gêneros Digitais e Ferramentas}

Vivemos hoje em uma sociedade caracterizada como sociedade da informação. O conjunto de tecnologias, as Novas Tecnologias de Informação e Comunicação NTICs como câmera de vídeo, webcam, cd e $d v d$, pendrive, cartões de memória, telefone móvel, TV por assinatura, e-mail, internet, podcasting, entre inúmeros outros, são muito comuns. Cada um desses itens, de uma forma ou de outra, permite-nos acessar, enviar e receber informações de modo mais fácil e rápido e, principalmente, criar e interagir.

Através do computador e do surgimento da internet e de sua difusão, a forma de interação e comunicação entre pessoas de diferentes lugares em diversas partes do mundo possibilitou diminuir a distância geográfica. As pessoas conseguem se comunicar mesmo com quem está em outro país, tanto por meio da linguagem oral e visual como pela linguagem escrita. $\mathrm{O}$ uso do texto digital tem se tornado cada vez mais frequente e uma nova linguagem o acompanha.

Ao tecer suas considerações acerca das reflexões em torno da escrita nos novos gêneros digitais da internet, Xavier [s.d.] afirma que "a internet tem levado as pessoas a lerem mais e a usarem mais a escrita. Dessa forma, muitos internautas têm ficado mais habilidosos no manuseio e na criação de formas específicas de lidar com a língua". Com isso a escrita foi ganhando novas formas, alterando o modo como as pessoas se expressam e, ao mesmo tempo, novos gêneros textuais surgiram, abrangendo de modo particular os usos da linguagem escrita e suas formas gráficas.

A noção de linearidade do texto também foi modificada, bem como o processo de leitura e escrita. Segundo Cereja e Magalhães (2008, p. 201):

$\mathrm{Na}$ internet o processo de ler ou escrever um texto deixou de ser linear, ou seja, da esquerda para a direita e de cima para baixo, um procedimento de cada vez. O internauta pode, simultaneamente ao processo de leitura de um texto, acessar links, ler outros textos, ouvir música, examinar imagens e planilhas, redigir e-mails e, finalmente, voltar a ler o texto que foi o ponto de partida para uma série de operações e de interações pela Internet. 
Percebemos aqui que o computador e, principalmente, a internet têm-se tornado mediadores de novas práticas de leitura e escrita, possibilitando diversas formas de interação com a linguagem textual. A essa interação que permite a uma pessoa inúmeras possibilidades de intercâmbio proporcionadas pelo texto digital e que permite de igual modo, acessar, produzir e interpretar informações dá-se o nome de hipertexto. "Assim, hipertexto exprime a ideia de leitura e escrita não linear de texto, em um contexto tecnológico, mediado pelo computador e pela Internet" (Cereja e Magalhães, 2008, p. 201).

A internet disponibiliza uma infinidade de informações de modo atrativo e dinâmico e segundo afirma Machado (2009, p. 122). Por ser um uso de linguagem digital que contém muitas outras, agregando vários textos, o hipertexto constitui um novo sistema de escrita e de leitura, por meio do qual os gêneros digitais se compõem, tornando possível uma ligação dinâmica entre os textos e partes de um mesmo texto através dos links digitais.

São bastante variados os gêneros textuais digitais. Conhecemos o e-mail, batepapo virtual (chat), listas de discussão, blogs, e muitos outros, cada um com uma linguagem específica para ser utilizada. Entretanto a maioria deles tem proximidade com os gêneros já existentes, como o e-mail e a carta, chats e conversas espontâneas, fóruns eletrônicos e seminários e debates, diários e agendas, cada um com suas especificidades ao usar a escrita. Um e-mail, por exemplo, pode ter maior ou menor grau de formalidade dependendo a quem é destinado. Marcuschi (2005, p. 13), ao discorrer sobre os gêneros textuais emergentes no contexto da tecnologia digital, faz questionamentos sobre a originalidade desses gêneros textuais digitais, sobre o fascínio que exercem e suas funções e chega à conclusão de que a reunião de várias mídias em um só meio favorece o sucesso que a nova tecnologia tem apresentado. E acreditamos que esses gêneros emergentes são ricos e podem ser explorados para promover a produção textual significativa dos nossos alunos.

No contexto educacional, surgem críticas em relação ao modo como os jovens escrevem utilizando as ferramentas digitais e questiona-se também por que nelas os alunos sentem-se bem ao escrever utilizando os mais variados gêneros textuais digitais e por outro lado, na sala de aula eles possuem dificuldades em produzir textos nos gêneros propostos pelo professor e até mesmo desinteresse. Sobre isso, Xavier [s.d.], afirma:

O advento da internet tem possibilitado a exposição de muitos adolescentes aos mais variados gêneros de textos e manifestações de linguagens que os das gerações anteriores. Lidar com essa nova mídia, conhecer e interagir com pessoas em diferentes pontos do planeta, sem dúvida, tem sido muito mais fascinante que ir à escola e esquentar as carteiras para ouvir o professor monotonicamente falar sozinho o tempo em que lá passamos.

Já sabemos que internet tem permitido aos jovens maior interação com os textos que circulam na rede em sua diversidade de gêneros, tornando-os cada vez mais receptivos e participativos. A utilização da linguagem na rede mundial de computadores pelos estudantes tem propiciado um novo olhar para a questão do ensino/aprendizagem e, igualmente, para a variação linguística promovida pelos gêneros digitais desenvolvidos neste novo espaço de interação.

No que diz respeito à linguagem utilizada, há os que veem a internet como algo negativo pela difusão do "internetês" e há também aqueles que a empregam como base para questionamentos para a produção textual em sala de aula. Sobre isso, Xavier (2007, p. 12) aponta para a criação de alternativas para lidar com o "tsunami linguístico" que a 
rede nos proporciona. Desta forma, não caberia ser totalmente contra ou a favor das novas linguagens utilizadas, mas valer-se do bom senso e saber harmonizá-las numa postura que ele chama de tecno-equilibrada.

Ao professor não cabe ignorar o fato de a tecnologia digital fazer parte do dia-adia do aluno, mas lançar mão dos recursos tecnológicos como armas fundamentais para tornar as aulas mais instigantes e apreciadas. É fundamental que estejam sempre atualizados e bem preparados para lidar com o novo recurso e, ao mesmo tempo passar os conteúdos previstos na grade currícular.

As novas tecnologias são ferramentas que podem servir de apoio às disciplinas escolares e que, além de atenderem às necessidades de interação, preparam o indivíduo para atuar em uma sociedade cada vez mais digital. Partindo deste pressuposto, Valente sugere que

o professor precisa conhecer as diferentes modalidades de uso da informática na educação - programação, elaboração de multimídia, uso de multimídia, busca da informação na Internet, ou mesmo de comunicação - e entender os recursos que elas oferecem para a construção de conhecimento. (Valente, 2005, p. 03)

A partir desta reflexão é possível perceber que, como educadores, é necessário aprender a lidar com os novos fenômenos linguísticos que vêm da internet e com outras inovações que surgem a todo instante em nossa sociedade. Tão importante quanto, é saber como lidar com os novos gêneros digitais no ambiente escolar de modo a fazer com que os alunos percebam a pluralidade de gêneros textuais e a necessidade de utilizarem adequadamente cada um deles.

Segundo Lais [s.d.], "a escola deve aproveitar a competência comunicativa dos adolescentes que usam bem os gêneros digitais disponíveis na rede virtual para transformá-los em bons produtores de gêneros textuais valorizados na sala de aula e no mundo real". Os usos dos gêneros digitais em sala de aula podem ser grandes ferramentas educacionais para o ensino e aprendizagem, propiciando ao aluno uma interação com tudo aquilo o que já faz parte de sua vivência.

\section{3) Várias formas de interação com as NTICs: possibilidades de produção textual coletiva por meio dos blogs}

Ao pensarmos nas inúmeras possibilidades de comunicação e interação que os gêneros digitais podem proporcionar, ampliando também a competência discursiva dos alunos, temos a preocupação de contribuir para o letramento digital do aluno, a partir do domínio de gêneros discursivos variados. No que se refere os gêneros digitais ou emergentes, Xavier (2005) afirma que eles poderiam ser mais bem explorados na e pela escola, principalmente para tornar as aulas de produção textual mais dinâmicas. Para esse autor, até mesmo a mudança de ambiente para um laboratório, para o caso de escolas que não possuam computadores em sala de aula, já torna a experiência empolgante. E acrescenta que a participação dos alunos proporciona ampliação em sua capacidade de argumentar sobre temas diversos e, desta maneira, refletir sobre os diferentes pontos de vista e construir opinião própria acerca do que discutem em aula..

Partindo desse pressuposto, Xavier (2005), ao tecer considerações sobre os blogs, msn, e-mail e orkut e o modo como podem contribuir para o ensino, afirma que, por se tratarem de um ambiente de conversação, no qual os interlocutores são levados a darem respostas imediatas e elaborarem seus próprios argumentos ainda que informais, podem auxiliar no desenvolvimento do adolescente mais do que se imagina. 
A Internet, utilizada como recurso pedagógico, possibilita uma nova prática de produção textual em que os alunos passam a desenvolver melhor uma atitude crítica em relação aos seus próprios textos e os dos demais colegas. Apesar de aqui terem sido citados alguns gêneros digitais, será dada maior ênfase ao gênero blog como forma de possibilitar o aluno a desenvolver-se em sua linguagem por meio da escrita colaborativa, visto que os jovens se interessam em expor fatos de seu cotidiano, pensamentos, observações e opiniões.

Também conhecido como weblog ou diário virtual, o blog é uma ferramenta bastante dinâmica, em que as pessoas podem publicar diariamente ou periodicamente seus textos na internet, além de links, fotos, músicas e vídeos, que são exibidos sempre da mais recente postagem para a mais antiga. Os textos postados são sempre acompanhados por uma janela para que os leitores possam fazer seus comentários a respeito. Desta forma, a cada postagem os visitantes podem deixar comentários, o que possibilita interação entre os internautas e a troca de ideias referentes ao que foi publicado.

Segundo o Jornal Folha de S. Paulo (2003), os diários virtuais vêm se popularizando cada vez mais devido à facilidade de uso, pois "com poucos cliques, qualquer internauta pode criar seu próprio diário virtual, mesmo que não tenha conhecimentos de programação". No campo educacional não é diferente. A utilização dos blogs também vem crescendo significativamente, visto que em sua maioria são gratuitos e de fácil manuseio, pois "como o sistema organiza automaticamente as mensagens (posts) do usuário, é bem mais fácil acrescentar textos a um blog do que a um site tradicional. Além disso, é possível criar diários coletivos, mantidos por vários usuários" (Folha São Paulo Online, 2003).

A escolha desse gênero digital foi feita tanto pelo fato de ser dinâmico e permitir maior facilidade para a edição, atualização e manutenção dos textos, como também pelo fato de não promover custos para o mantenedor, como já vimos. Desta forma, para criar um blog é necessário apenas um computador e estar conectado à rede. "Enquanto montar um site exige ter conhecimento de programação de computadores ou pagar por essa acessoria, criar uma página na rede é simples e rápido. Há diversos programas de hospedagem de blogs disponíveis gratuitamente na Internet." (Cereja e Magalhães, 2008, p. 202).

A utilização dos blogs na educação como recurso didático e, ao mesmo tempo, como meio de comunicação virtual permite a criação de novas estratégias de ensinoaprendizagem em diversas áreas do conhecimento, despertando o interesse e a motivação em sala de aula e ampliando conhecimentos. Alunos e professores podem trocar experiências, expor projetos e trabalhos, expressar ideias, redigindo e postando seus textos com direitos a comentários e opiniões.

Atualmente, há milhares de blogs espalhados pela rede abordando diferentes temáticas. Marcuschi (2005) refere-se ao blog como um gênero emergente na mídia virtual, atualmente absorvido por jovens e adultos que o utilizam com as mais variadas finalidades, sejam elas pessoais ou profissionais e até mesmo blogs comunitários, podendo ser, por exemplo, do grupo de estudos, da turma de amigos, da classe:

(...) os blogs funcionam como um diário pessoal na ordem cronológica com anotações diárias ou em tempos regulares que permanecem acessíveis a qualquer um na rede. Muitas vezes, são verdadeiros diários sobre a pessoa, sua família ou seus gostos e seus gatos e cães, atividades, sentimentos, crenças e tudo o que for conversável (Marcuschi, 2005, p. 61). 
O blog pode ser utilizado tanto para educação à distância quanto para aulas presenciais e em sala de aula, de acordo com a disciplina trabalhada, atua como um suporte para pesquisas e produção de forma bastante abrangente. Nas aulas de língua portuguesa e produção textual, por exemplo, é um facilitador da escrita e da leitura, em que, como proposta de atividade, os alunos podem expor seus próprios textos de forma com que também melhorem suas habilidades de escrita.

Segundo Murano (2011, p. 32), "educadores e especialistas em linguagem são unânimes ao afirmar que o cultivo de um blog pessoal traz benefícios às habilidades de escrita e de leitura". Por meio dos blogs, os alunos têm a possibilidade de escrever e editar seus próprios textos de forma imediata. Os blogs possibilitam aos alunos lidar com o processo de revisão e reelaboração da escrita e, ao mesmo tempo, com a construção de argumentações, como já citado.

De acordo com os PCNs, o aluno deve ser capaz de produzir textos coerentes, coesos, adequados a seus destinatários, aos objetivos a que se propõem e aos assuntos tratados; utilizar diferentes registros, inclusive os mais formais da variedade linguística valorizada socialmente, sabendo adequá-los às circunstâncias da situação comunicativa de que participam. (PCNs. 1998, pp. 95-98). Desta forma, na prática de produção de textos cuja ferramenta utilizada é o blog, o maior objetivo é formar escritores capazes de produzir textos coerentes, coesos e eficazes naquilo o que se deseja transmitir e também fazer com que os alunos tenham uma atitude crítica em relação à sua própria produção de textos.

A escrita colaborativa por meio do blog, proposta deste trabalho, é uma excelente estratégia para aprimorar a escrita dos alunos com as postagens e fazer com que eles escrevam e produzam textos excelentes sem que se sintam pressionados, atribuindo a cada tópico acrescido, um sentido, de forma contextualizada. Sendo o blog uma ferramenta na qual todos podem acessar e fazer comentários, os alunos buscarão minimizar seus erros e poderão ainda enriquecer suas produções com links, fotos, ilustrações e sons.

Para realização de um projeto com blogs em sala de aula, o professor pode, por exemplo, desenvolver inicialmente um trabalho associando a leitura à oralidade, selecionando e distribuindo livros adequados à série para que, em suas casas, os alunos realizem a leitura dos mesmos e na semana seguinte relatem ao restante da turma. $\mathrm{O}$ ideal é que os alunos possam escolher dentre os livros expostos, o de sua preferência, pois facilita para uma leitura prazerosa. Em um segundo momento o professor já poderá solicitar que os relatos sejam transformados em textos utilizando os blogs.

Após o primeiro relato oral e escrito o próximo passo é fazer o rodízio dos livros para que todos conheçam as histórias que os colegas leram e possam, desta forma, acrescentar informações naquilo o que foi produzido sobre o livro lido em uma produção aberta, pois poderá ser lido por outras pessoas, colegas de classe ou não, que poderão acessar e interagir através de comentários. Os alunos poderão tanto colocar sua opinião sobre as histórias quanto relatá-las a partir de seu entendimento sobre a leitura.

Além dessa atividade podem ser desenvolvidas muitas outras. O professor lançar debates sobre determinados assuntos ou textos para que os alunos discutam as ideias; dar continuidade a um trabalho coletivo iniciado em sala de aula; pedir para que os alunos criem poesias e publiquem a partir de uma aula de literatura, pedir para que alimentem o blog com informações diversas; postar fotos das atividades realizadas no decorrer do ano letivo para que os alunos relatem a importância de cada momento registrado, etc. Em resumo, a utilização dos blogs em sala de aula pode se realizar de diversas maneiras servindo, principalmente, para expor os conhecimentos adquiridos pela turma no decorrer das aulas ou demais atividades pedagógicas. 
No trabalho com o blog o aluno, como avaliador de seu próprio texto, faz reflexões e busca melhorá-lo, pois será visto por outras pessoas que de igual modo irão avaliá-lo. Entretanto, fazer com que os alunos sejam capazes de construir argumentações e lidar reflexivamente com a ortografia, o processo de monitoração, revisão e reelaboração da escrita on-line requer conhecimento por parte do professor e um trabalho bastante supervisionado para a utilização adequada das ferramentas digitais.

As ferramentas tecnológicas não atuam por si só. É importante que o professor planeje adequadamente as atividades a serem realizadas para que as mesmas sejam produtivas e, de fato, auxiliem os alunos no desenvolvimento da escrita e da leitura. $\mathrm{O}$ professor deve, sobretudo, atuar como mediador na construção da escrita adequada do aluno e estar sempre acompanhando e orientando as pesquisas.

Segundo a Revista Nova Escola (online), ao montar um blog com os alunos, o professor deverá se preparar para enfrentar o dilema de corrigir ou não a grafia das palavras, pois durante a comunicação via internet é comum a utilização de um código bastante particular, caracterizado por abreviações e pela invenção de novas formas de escrever, como já vimos.

Apesar deste impasse, é importante que o professor explicite aos alunos as variações linguísticas e seus usos, os quais devem ser adequados a cada situação de comunicação, e que estabeleça com a turma a linguagem a ser utilizada. Como aqui o objetivo é o desenvolvimento da linguagem escrita dos alunos por meio da produção de texto coletivamente, o ideal é que opte pela linguagem de norma culta ainda que o ambiente seja um espaço fruto da cultura da internet que "nasceu" com os jovens e em que todos poderão se expressar livremente. Entretanto, isso não impede que nas ocasiões de mensagens informais entre os alunos, o professor permita a publicação de mensagens com as características do texto cibernético. Xavier [s.d.], ao fazer reflexões em torno da escrita e os novos gêneros digitais sugere que

o professor de Língua Portuguesa peça que os alunos construam ou tragam um texto produzido em um gênero digital com todas as abreviações e reduções que lhes são peculiares e, depois, o "traduzam" ou o retextualizem. Assim, eles poderão perceber no processo de transformação as diferenças entre os gêneros textuais e a necessidade de grafar as palavras de uma certa maneira, considerando o contexto situacional da produção daquele texto agora retextualizado.

Ao saber que o texto se tornará público e lido por outras pessoas, é provável que os alunos tenham mais cuidado com a forma e o conteúdo daquilo o que irão postar, procurando deixar as ideias bem claras e tentando minimizar os erros. É por esse motivo que propomos a utilização do blog como ferramenta didática para estimular a escrita criativa, em colaboração e com maior significado pessoal para os alunos do ensino fundamental.

\section{4) Considerações Finais}

Sabemos que as tecnologias digitais presentes no cotidiano de nossos alunos já estão se inserindo e transformando as práticas pedagógicas. Por isso neste artigo foram explicitadas algumas reflexões a respeito das NTICs - Novas Tecnologias de Informação e Comunicação e, de igual modo, como os blogs podem ser utilizados em sala de aula de modo a atuar no processo ensino/aprendizagem trazendo benefícios ao desenvolvimento da linguagem escrita por meio das postagens. 
O blog, como ferramenta digital utilizada para desenvolver a competência de escrita nos alunos faz com que produzam textos espontâneos e com maior liberdade não apenas para o professor, mas para um público maior, o que o fará pensar de maneira mais cuidadosa e ao mesmo tempo, um tanto quando desligada da ideia de obrigatoriedade ao realizar uma atividade escolar proposta. O trabalho com os blogs colabora na formação linguística dos seus usuários, pois tende a fazer dos mesmos leitores e autores de textos sejam verbais, visuais, sonoros ou hipertextuais.

Diante do grande desenvolvimento das novas tecnologias e o modo como vêm imprimindo mudanças em nosso meio vê-se a importância de a escola não se fechar para essa realidade na qual estamos inseridos. As ferramentas disponíveis na internet oferecem um universo de possibilidades a ser explorado por professores e alunos como alternativa criativa e estimulante no processo de produção de texto.

Acreditamos que não se deve impedir que os alunos utilizem os gêneros digitais, sob o pretexto de que prejudicam a aprendizagem da escrita "correta". Isso nada mais é que ignorar a variação linguística existente em nossa língua. E, ainda pior, deixar de cumprir o papel de incluir digitalmente nossos alunos. Portanto, cabe ao professor e à escola estarem abertos às novas ferramentas, gêneros digitais e às inovações que aparecem a todo instante, de modo a aproveitar a competência comunicativa dos adolescentes, já que usam bem os gêneros digitais disponíveis na rede virtual, para torná-los produtores de textos mais significativos e nos quais o exercício de autoria seja o foco principal.

\section{5) Referências Bibliográficas}

ANDRADE, Leila Minatti. A escrita, uma evolução para a humanidade. Revista Linguagem em (Dis)curso, volume 1, número 1, jul./dez. 2001. Disponível em http://www3.unisul.br/paginas/ensino/pos/linguagem/0101/12.htm. Acessado em $12 \mathrm{de}$ abril de 2012.

CASTILHO, Alceu Luís. Escrita criativa: Revista Língua Portuguesa. São Paulo: Editora Segmento, pp. 42-47. Ano 6, nº 70, agosto de 2011.

CEREJA, Willian Roberto e MAGALHÃES, Thereza Cochar. Português: linguagens: volume I. $6^{\text {a }}$ ed. reform. - São Paulo: Atual, 2008.

FOLHA DE SÃO PAULO - 2003. Diários virtuais se popularizam na Internet. Disponível em http://www1.folha.uol.com.br/folha/informatica/ult124u12364.shtml. Acessado em 17 de junho de 2012.

FREITAS, Maria Teresa de Assunção. Da tecnologia da escrita à tecnologia da internet. In FREITAS, Maria Teresa de Assunção e COSTA, Sérgio Roberto (orgs.). Leitura e escrita de adolescentes na internet e na escola. $2^{\mathrm{a}}$ ed - Belo Horizonte: Autêntica, 2006.

FUHRMANN, Leonardo. Arquitetura das ideias: Revista Língua Portuguesa. São Paulo: Editora Segmento, pp. 38-42. Ano 7, nº 74, dezembro de 2011. 
GENTILE, Paola. Revista Nova Escola. Blog: diário (de aprendizagem) na rede. Disponível em http://revistaescola.abril.com.br/lingua-portuguesa/praticapedagogica/blog-diario-423586.shtml. Acessado em: 21 de junho de 2012.

GUERREIRO, Carmem. Deu branco! Revista Língua Portuguesa. São Paulo: Editora Segmento, pp. 36-41. Ano 5, nº 68, junho de 2011.

KOCH, Ingedore Villaça e ELIAS, Vanda Maria. Ler e escrever: estratégias de produção textual. - $2^{\mathrm{a}}$ ed. - São Paulo: Contexto, 2011.

LAIS, Cláudia. O uso dos gêneros digitais na sala de aula. Anais eletrônicos do I simpósio regional de educação/ comunicação. Disponível em: https://docs.google.com/viewer?a=v\&q=cache:qkorxo70br8j:ead.unit.br/simposioregion al/htm/download.php?file\%3d../gt02/generos_digitais.pdf+os+usos+dos+generos+digita is + na + sala + de+aula\&hl=ptbr\&gl=br\&pid=bl\&srcid=adgeesgpd 7 srvgiy70iiepihsbugkrar 9j_erpt8t9fs_zeoargti9_oaqmpkcz2x5ajiu3rflpuc_snfsnu4bkd_gb0t7vnyqrkvatyyhshhk8 rt1j0yvghfj4lnteflge_-j1nq67h\&sig=ahietbq6x4ujibniphidpnhv4b5o14bnyg.

Acessado em: 13 de maio de 2012.

MACHADO, Irene. Gêneros digitais e suas fronteiras na cultura tecnológica. Revista Educação e Tecnologia. Periódico Técnico Científico dos Programas de Estudos PósGraduados em Comunicação em Tecnologia dos CEFETs - PR/MG/RJ, pp. 117-128. Ano 4, nº 6, maio de 2003.

MARCUSCHI, Luiz Antônio e XAVIER, Antônio Carlos (orgs.). Hipertexto e gêneros digitais: novas formas de construção do sentido. $-2^{a}$ ed. Rio de Janeiro: Lucerna, pp. 13-67, 2005.

MURANO, Edgard. O texto na era digital: Revista Língua Portuguesa. São Paulo: Editora Segmento, pp. 28-33. Ano 5, nº 64, fevereiro de 2011.

Parâmetros Curriculares Nacionais: terceiro e quarto ciclos do Ensino Fundamental: Língua Portuguesa/Secretaria de Educação Fundamental. Brasília: MEC/SEF, 1998.

SAMPSON, Geoffrey. Sistemas de escrita: tipologia, história e psicologia. São Paulo: Ática, 1996.

VALENTE, José Armando. Pesquisa, comunicação e aprendizagem com o computador. Disponível em: http://cmapspublic.ihmc.us/rid=1HXFXQKSB23XMNVQ-M9/VALENTE_2005.pdf. Acessado em: 29 de abril de 2012.

XAVIER, Antônio Carlos. Gêneros textuais emergentes no contexto da tecnologia digital. In: MARCUSCHI, Luiz Antônio e XAVIER, Antônio Carlos (orgs.). Hipertexto e gêneros digitais: Novas formas de construção de sentido. $2^{\mathrm{a}}$ ed. Rio de Janeiro: Lucerna, 2005, p.13-67.

in ARAÚJO, Júlio César (org.). Internet e ensino: Novos gêneros, outros desafios. Rio de Janeiro: Lucerna, 2007. 
+ Disponível em: http://www.ufpe.br/nehte/midia-artigos-pesquisadores.html. Acessado em: 13 de maio de 2012. 